\title{
Laboratory Evaluation of Biorational and Low Risk Insecticides and Their Mixtures for Management of Diamondback Moth Larvae
}

\author{
Matthew Conklin Flanery, Henry Ofosuhene Sintim, Beatrice Nuck Dingha and Louis Ernest Jackai \\ Department of Natural Resources and Environmental Design, North Carolina Agricultural and Technical State University, Carver \\ Hall, 1601 East Market St., Greensboro NC 27411, USA
}

\begin{abstract}
The diamondback moth, Plutella xylostella L., has developed resistance to most insecticides used for its management. Suggested alternatives to forestall this process include biorational insecticides in mixtures with low-risk insecticides. The aim of this study was to select an insecticide or insecticide mixture that could be adopted by small-scale growers for diamondback moth management. The effectiveness of four insecticide mixtures, i.e., Agroneem ${ }^{\circledR}$ Plus (neem-derived), Spinosad (microbial origin), thiamethoxam (neonicotinoid) and a homemade methanol Jalapeño pepper extract, in laboratory bioassays was evaluated. Binary mixtures were tested against single products at manufacturer's label rates. These were applied to collard greens using the leaf dip method and fed to the newly molted 2nd or 3rd instar larvae. Mixtures were evaluated for efficacy based on larval mortality and consumption of leaf discs. The results showed interactions between Jalapeño pepper extract and Spinosad and between the neem-derived Agroneem ${ }^{\circledR}$ Plus and thiamethoxam at some of the tested concentrations. Mixtures with at any amount of Spinosad killed all larvae. The neem-based product gave inconsistent results in some treatments; in some case, increased leaf damage did not result in commensurate larval mortalities. The reported resistance of diamondback moth larvae to Spinosad was not observed during this study, neither with Spinosad alone nor in mixtures.
\end{abstract}

Key words: Agroneem, diamondback moth management, insecticide mixtures, Spinosad, thiamethoxam.

\section{Introduction}

Crucifers are grown worldwide and are popular vegetables grown in North Carolina and elsewhere in the United States. They include cabbage, broccoli, cauliflower, radish, kohlrabi, kale and collard. Collard greens, Brassica oleracea L. (Acephala group), play a key role in traditional Southern US cuisine [1]. Collard is the most common leafy green grown by small farmers in Southern US; it is an important source of family income in North Carolina, which produced $243,000 \mathrm{cwt}$ (12,345 metric tons) of collard and was worth $\$ 6,318,000$ in 2001 , and is ranked the third nationally behind Georgia and South Carolina [2]. This accounted for more revenue to North Carolina than any other leafy green. Insects are a

Corresponding author: Louis Ernest Jackai, Ph.D., research fields: applied insect ecology and integrated pest management. major constraint in the production of collard and other brassica crops. The diamondback moth Plutella xylostella L. (Lepidoptera: Yponomeutidae), the small white butterfly Pieris rapae L. (Lepidoptera: Pieridae), the cabbage looper Trichoplusia ni Hübner (Lepidoptera: Noctuidae), the harlequin bug Murgantia histrionica Hahn (Hemiptera: Pentatomidae), Brevicoryne brassicae L. (Hemiptera: Aphididae) and Myzus persicae Sulzer (Hemiptera: Aphididae) constitute the key insect pest complex on brassicas. Worldwide, P. xylostella poses significant economic risk to brassica production [3, 4]. It is estimated that the combined effects of P. xylostella and $P$. rapae reduce potential yields of crucifers, including collard greens, by as much as $40 \%$ [5]. The diamondback moth costs brassica producers over US\$ 1 billion per year worldwide in damage and 
control costs; damage is inflicted on the marketable leafy edible portion of the plant [6].

Consumers have an extremely low tolerance for damage from caterpillars, including the diamondback moth, and only trace amounts of insect damage or frass is accepted in produce [7]. Increasing and sustained demand from consumers, public and private entities to reduce pesticide use on crops creates a dilemma for collard and other vegetable growers [8]. There are acceptable alternatives for use by small-scale growers, including bio-pesticides that enhance biodiversity, cultural manipulations and use of low risk conventional pesticides which can replace high risk products, or a combination of these strategies. However, bio-pesticides are not as effective as their synthetic relatives and thus tend to be applied more frequently. The diamondback moth has the ability to rapidly develop resistance to the different insecticide groups that have been used for its control [9], and this includes biopesticides. On average, a new insecticide is expected to have a utility life of just two to three years in any crucifer production system [10]. Insecticide mixtures with proven synergistic interaction can present an array of toxic molecules and consequently prolong the usefulness of the individual insecticides [11]. Such chemical diversity would eventually slow down the onset or progression of resistance to insecticides $[12,13]$.

Biorational insecticides, including botanical and microbial insecticides, have several advantages over their conventional relatives; they have little or no adverse effects on non-target organisms or on the environment. In addition, they can be used in conjunction with biological control agents [14], often as single chemistries with success barring the development of resistance. A classical case of this was in connection with diamondback moth control with Spinosad in Hawaii [15]. In another case, Bacillus thuringiensis $(\mathrm{Bt})$ strains became ineffective with time [16] as a result of diamondback moth resistance. But despite reports of resistance, when used as a spray Spinosad controls many pest complexes, such as caterpillars, thrips [17] and beetles [18] on several crops [19]. Thiamethoxam, one of the insecticides used in this study, is a low risk neonicotinoid insecticide that is especially effective against sucking insects [20] on crucifers. It is selective, and has a short re-entry interval and low environmental impact. Insecticides, such as the neem-derived azadirachtin-containing products and other crude plant extracts, have been used with fairly satisfactory results in the control of diamondback moth larvae when used individually [21]. Also a number of home-made insecticides, such as pepper extract which could be readily obtained and used by small growers, have found their way in smallholder pest control practices.

Experiments were designed to investigate the efficacies of three biorational and a representative low risk insecticide in different binary combinations [12]. The four pesticides tested were used singly at low and high concentrations and up to six binary combinations. Two of the biorational insecticides (the neem-derived and the pepper extract) are commonly used by small growers in tropical countries, while neem products have a growing market here in the US. Given the assumption that pesticide effects are additive [22], the study was driven by three hypotheses: (1) when each pesticide is present alone, high concentrations will cause lower survival and damage than low concentrations; (2) when two pesticides are combined, pest survival and crop damage will be lower than with either pesticide alone at low concentrations; (3) when two pesticides are combined, survival and growth will be intermediate to either pesticide alone at high concentration (assuming that the two pesticides cause different effects when used alone). These anchored the ultimate goal of the study, which was to select an insecticide or insecticide combination that could be adopted by small-scale growers for diamondback moth management. 


\section{Materials and Methods}

\subsection{Diamondback Moth Culture}

A laboratory strain of the diamondback moth collected from collards growing at the North Carolina Agricultural \& Technical State University (NCA\&TSU) Research Farm, in Greensboro, NC, United States of America, in the fall of 2010 for the bioassays was used in the studies reported here. Based on the field observations, there appeared to be no indication of pesticide resistance to Spinosad in this population. The insects were subsequently reared on collard (Georgia Southern variety) leaves held in place by cotton wool in the mouth of Kilner jars half-filled with water. These were placed in plastic containers $(14.5 \times$ $10.5 \times 10.6$ inches) (Super Wal-Mart, Greensboro, NC, USA). The insects were maintained in this way for at least eight generations under laboratory conditions. The leaves were changed frequently to avoid decay. The test insects had a life cycle that lasted about $18 \mathrm{~d}$ at normal room conditions (about $27{ }^{\circ} \mathrm{C} ; 14: 10$ light/dark photoperiod; $50 \%$ relative humidity).

\subsection{Insecticides}

Four insecticides were selected for the study based on preliminary studies, namely, a neem-based product Agroneem ${ }^{\circledR}$ Plus (Agrologistic Systems Inc., Diamond Bar, CA), Spinosad (Monterey ${ }^{\circledR}$ Garden Insect Spray, Lawn and Garden Products, Inc., Fresno, CA), the neonicotinoid thiamethoxam (Actara ${ }^{\circledR}$ : Syngenta Crop Protection Inc., Greensboro, NC) used as a reference synthetic insecticide that controls sucking pests, and crude methanolic extract of Jalapeño peppers, Capsicum annuum L. (1:2 w/v) [23] obtained by blending in a kitchen mixer (Black \& Decker-10 speed blender, Wal-Mart, Greensboro, NC), then filtering through a Fisher Brand Whatman \#4 filter paper and the filtrate was kept in a glass jar at $0{ }^{\circ} \mathrm{C}$ until needed. The choice of Spinosad and thiamethoxam was driven by results from unpublished field experiments, which indicated that in combination they provided excellent control of caterpillars, stink bugs and other pests found on collard.

\subsection{Bioassay Procedures}

Five experiments were carried out to determine the efficacy of three commercial insecticides and the crude methanol extract of Jalapeño peppers against the diamondback moth larva using collard leaf discs. The method described for the pepper extract at $250 \mathrm{~mL} / \mathrm{L}$ was precisely followed as described in Ref. [24] and then diluted as described below. Four single insecticides, six insecticide combinations and a control were tested. The treatments were: (1) the neem-based Agroneem ${ }^{\circledR}$ Plus; (2) pepper; (3) Spinosad; (4) thiamethoxam; (5) Agroneem ${ }^{\circledR}$ Plus + pepper (AP); (6) Agroneem ${ }^{\circledR}$ Plus + Spinosad (AS); (7) Agroneem $^{\circledR}$ Plus + thiamethoxam (AT); (8) pepper + thiamethoxam (PT); (9) pepper + Spinosad (PS); (10) Spinosad + thiamethoxam (ST); (11) a water control. The leaf dip bioassays [11] were conducted to determine the response of diamondback moth larvae to ingestion of the insecticides. Leaf tissue $(10 \mathrm{~cm}$ in diameter) was cut from uninfected collard plants grown outdoors in the NCA\&TSU Research Farm. Individual leaf discs were immersed in a prepared insecticide solution for $3 \mathrm{~s}$ and allowed to air dry for 2 h. Control leaves were treated similarly with tap water. Filter paper (Whatman No. 5, $90 \mathrm{~mm}$ ) was placed inside an $8.750 \mathrm{~cm}$ diameter plastic Petri dish, and the leaf discs placed on top of the filter paper. Five randomly selected 2 nd or early 3 rd instar larvae of the diamondback moth from the laboratory culture were released in each Petri dish and held at about $27{ }^{\circ} \mathrm{C}$, 14:10 light/dark photoperiod and $50 \%$ relative humidity. The treatments were replicated three times (three Petri dishes per concentration), and larval mortality was recorded as described previously. The experiment was repeated once, thus making an overall total of six replications.

Leaf discs were divided with marks into four quadrants and each assessed over $25 \%$. An insect was 
considered dead, if it did not respond to probing with a blunt object. Leaf area damage was estimated visually and recorded on a scale of $5 \%$ increments. Following the general procedures, a set of five sequential experiments were designed to address different questions. In each case, leaf (disc) damage and larval mortality were monitored as indicated. The experiments were as follows:

2.3.1 Efficacy of Insecticides at Recommended and Half of the Recommended Rates

The first of the experiments involved exposure of the larvae as described above to the manufacturer's label rate and a concentration obtained by halving this rate.

2.3.2 Efficacy of Insecticides at the Label Rate, Double $(2 \times)$ and One-Fourth $(0.25 \times)$ of the Label Rates

The same procedure of $0.25 \times, 1 \times$ and $2 \times$ of the label rate of each insecticide was followed as described above. A bioassay-guided approach was used in selecting the dilutions in that dilutions were made the mortality and damage results obtained guided us on the subsequent concentrations and end-points to be adopted. Leaf consumption and larval mortality were recorded at 24,48 and $72 \mathrm{~h}$ after larvae were introduced.

2.3.3 Efficacy of Insecticide Mixtures at Ratios of $2: 1,1: 1$ and $1: 2$

Following the first two experiments indicated above of single insecticides, the best rates obtained were used to evaluate mixtures of different insecticides used in experiments 2.3.1 and 2.3.2 above. This was to determine the nature of interactions (synergistic or additive) between insecticide products. Of interest were mixtures using only biorational products on the one hand targeting organic production, and mixtures between biorational and low-risk insecticides on the other for use in non-organic growers. Insecticide mixtures in different proportions were used in bioassays to identify possible interactions. These experiments were conducted using different rates of all six possible combinations (AP, AS, PS, AT, PT and ST). Larval mortality and leaf consumption were recorded initially at $24 \mathrm{~h}$ and $72 \mathrm{~h}$, and subsequently 24, 48 and $72 \mathrm{~h}$ for the evaluation of leaf feeding in the comparison of insecticide label rates. Significant differences were not observed at $48 \mathrm{~h}$ during initial evaluations.

2.3.4 Efficacy of Insecticide Mixtures at the Ratios of $4: 1$ and $1: 4$

The results obtained for the ratio 2:1 indicated that some of the mixtures could be further diluted. Four of the mixtures (AP, PS, AT and ST) that showed high efficacy were selected for the 4:1 dilution. These mixtures were used in this and the next experiment. Larvae were monitored and leaf consumption and mortality were recorded at $24 \mathrm{~h}$ and $72 \mathrm{~h}$ as before.

2.3.5 Efficacy of Insecticide Mixtures at the Ratios of $8: 1$ and $1: 8$

Larvae were exposed to leaf discs at the 1:8 ratio of the different mixtures: AP, PS, AT and ST and monitored for leaf consumption and mortality at $24 \mathrm{~h}$ and $72 \mathrm{~h}$.

\subsection{Data Analysis}

Data were analyzed using XLSTAT 2012 and non-parametric Kruskal-Wallis one-way analysis of variance was performed to detect the differences in leaf consumption or damage and mortality among the insecticide treatments and the untreated control. Mean values were compared using Duncan's multiple range test (DMRT). Values were considered significantly different at $P \leq 0.05$. Abbott's formula [25] was used to correct for mortality.

\section{Results}

\subsection{Efficacy at Reduced and Increased Rates}

The efficacy of three commercial insecticides and a crude pepper extract tested against diamondback moth larva at reduced and increased application rates are summarized in Table 1 and Fig. 1. The percent of leaf damage and larval mortality were different in the various 
Table 1 Percent of leaf damage ${ }^{1}$ by the diamondback moth larva on collard greens leaf discs ${ }^{2}$ treated with different rates of insecticides in laboratory bioassays.

\begin{tabular}{|c|c|c|c|c|c|c|c|c|c|c|c|c|}
\hline \multirow{3}{*}{ Insecticides $^{3}$} & \multicolumn{12}{|c|}{ Percent of leaf damage (\%) after different exposure time in different rates } \\
\hline & \multicolumn{3}{|c|}{$2 \times$ label } & \multicolumn{3}{|c|}{$1 \times$ label } & \multicolumn{3}{|c|}{$0.5 \times$ label } & \multicolumn{3}{|c|}{$0.25 \times$ recommended } \\
\hline & $24 \mathrm{~h}$ & $48 \mathrm{~h}$ & $72 \mathrm{~h}$ & $24 \mathrm{~h}$ & $48 \mathrm{~h}$ & $72 \mathrm{~h}$ & $24 \mathrm{~h}$ & $48 \mathrm{~h}$ & $72 \mathrm{~h}$ & $24 \mathrm{~h}$ & $48 \mathrm{~h}$ & $72 \mathrm{~h}$ \\
\hline Agroneem ${ }^{\circledR}$ Plus & $8.3^{\mathrm{b}}$ & $10.0^{\mathrm{b}}$ & $10.0^{\mathrm{b}}$ & $11.7^{\mathrm{ab}}$ & $16.7^{\mathrm{b}}$ & $23.3^{\mathrm{b}}$ & $28.3^{\mathrm{b}}$ & - & - & $18.3^{\mathrm{bc}}$ & $28.3^{\mathrm{ab}}$ & $36.7^{\mathrm{ab}}$ \\
\hline Spinosad & $0.0^{\mathrm{a}}$ & $0.0^{\mathrm{a}}$ & $0.0^{\mathrm{a}}$ & $0.0^{\mathrm{a}}$ & $0.0^{\mathrm{a}}$ & $0.0^{\mathrm{a}}$ & $6.7^{\mathrm{a}}$ & - & - & $0.0^{\mathrm{a}}$ & $0^{\mathrm{a}}$ & $0^{\mathrm{a}}$ \\
\hline Thiamethoxam & $0.0^{\mathrm{a}}$ & $0.0^{\mathrm{a}}$ & $0.0^{\mathrm{a}}$ & $0.0^{\mathrm{a}}$ & $0.0^{\mathrm{a}}$ & $0.0^{\mathrm{a}}$ & $10.0^{\mathrm{a}}$ & - & - & $5.0^{\mathrm{ab}}$ & $11.7^{\mathrm{ab}}$ & $20.0^{\mathrm{ab}}$ \\
\hline Control & $28.3^{\mathrm{c}}$ & $60.0^{\mathrm{c}}$ & $80.0^{\mathrm{c}}$ & $28.3^{\mathrm{c}}$ & $60.0^{\mathrm{c}}$ & $80.0^{\mathrm{c}}$ & $21.7^{\mathrm{ab}}$ & - & - & $28.3^{\mathrm{c}}$ & $60.0^{\mathrm{b}}$ & $80.0^{\mathrm{b}}$ \\
\hline
\end{tabular}

Teaf area damage was estimated visually and recorded in $5 \%$ increments; ${ }^{2}$ the leaf discs were divided into four quadrants and each was assessed per $25 \% ;{ }^{3}$ these were straight insecticides at the label recommended rate.

${ }^{\text {a-c }}$ Means with the same superscript in a column are not significantly different at $P>0.05$.

-: These experiments were not monitored after $24 \mathrm{~h}$ and thus none of the insecticide treatments significantly different from the control. 


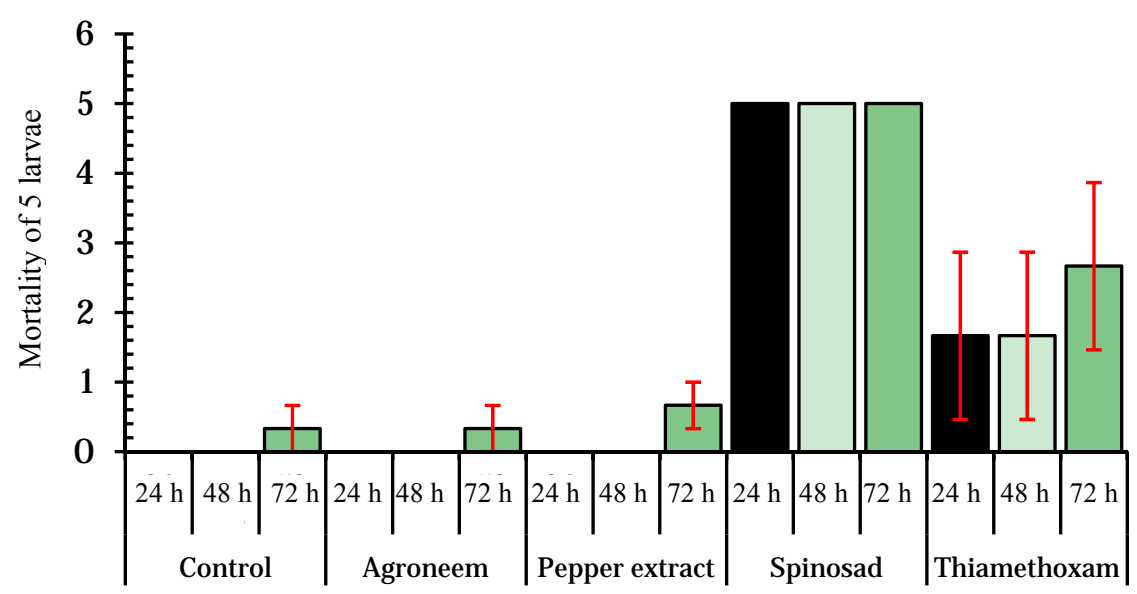

(a) $0.25 \times$ label rate

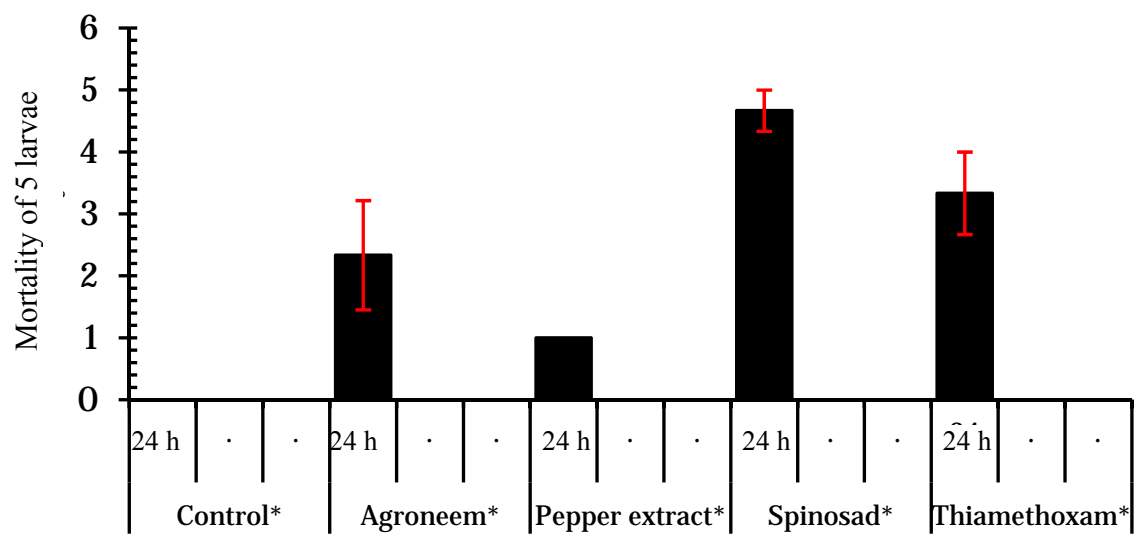

(b) $0.5 \times$ label rate

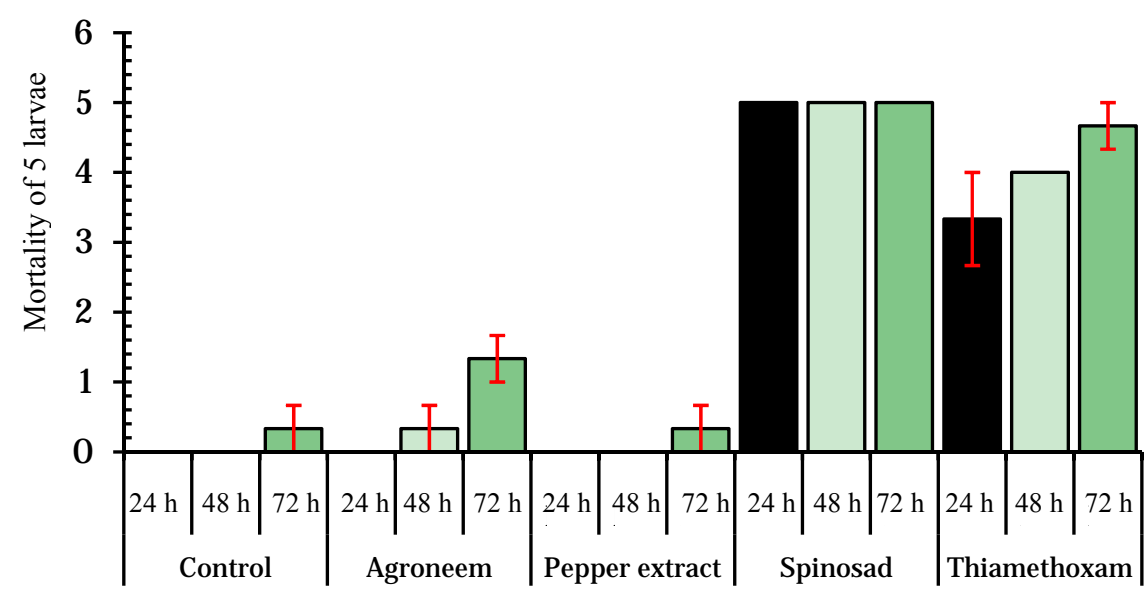

(c) $1 \times$ label rate 


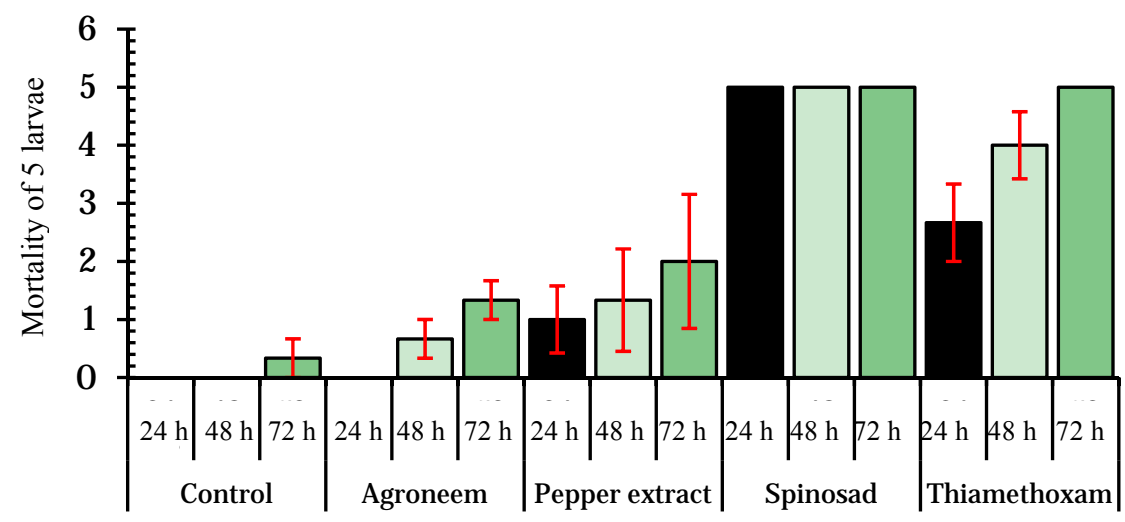

(d) $2 \times$ label rate

Fig. 1 Effect of insecticides at reduced and increased rates of the label recommendation on mortality of diamondback moth larvae over time in laboratory bioassays.

- These experiments were not monitored after $24 \mathrm{~h} . *$ These were straight insecticides at label rates.

treatments. The label and half the label rates were similarly effective in killing diamondback moth larvae. At these two rates, however, Spinosad and thiamethoxam gave significantly $(P<0.05)$ better protection than Agroneem, pepper extract and control. Agroneem and pepper extract were not different from the control $(P>0.05)$. In subsequent bioassays using a double $(2 \times)$ and a fourth $(0.25 \times)$ of the label application rates, the $2 \times$ rate was not significantly different from the label or the $0.25 \times$ rate $(P>0.05)$. Thiamethoxam treatment had a significantly higher mortality $(P<0.05)$ in the other application rates $(2.7 \%-3.3 \%)$ than the $0.25 \times$ rate $(1.7 \%)$. Spinosad was effective at all tested rates (Fig. 1) and provided the highest $24 \mathrm{~h}$ larval mortality. Leaf discs that had been treated with both thiamethoxam and Spinosad were hardly nibbled, suggesting a high level of antifeedant activity. They had similar lethal effects on the larval mortality (Fig. 1), although this was higher for Spinosad after $24 \mathrm{~h}$. When the concentration of thiamethoxam was doubled, it resulted in a negligible increase in mortality; however, the $25 \%$ dilution had a significant reduction in mortality. Spinosad was effective at all the concentrations tested. In the Spinosad treatments, larval mortality was $100 \%$ after $24 \mathrm{~h}$. Agroneem and pepper, like the control, did not cause significant larval mortality (Fig. 1) and resulted in only a limited antifeedant reaction (Table 1).

Concomitantly, Agroneem at all the tested concentrations had significantly lower $(P<0.05)$ leaf damage than the control. Treatments with Agroneem and pepper extract at $2 \times$ label rate were effective in reducing leaf damage (Table 1), suggesting anti-feedant action with only marginal larval mortality (Fig. 1). Treatments that were effective after $24 \mathrm{~h}$ sustained their effectiveness for the test duration. The effectiveness of Agroneem was slightly enhanced at the $2 \times$ label rate than at the reduced or label rates (Table 1). Overall, pepper extract was the least effective among the insecticide treatments. Concentrations of the pepper extract were only marginally effective at the $2 \times$ label application rate. The $0.25 \times$ label rate of the pepper extract performed better than the undiluted extract, but was not significantly different $(P>0.05)$. An important point to note is that the increased rates for each insecticide did not enhance their efficacy (Table 1 and Fig. 1).

\subsection{Effect of Insecticide Mixtures on Larval Activities}

Spinosad performed extremely well in all mixtures in any of the proportions tested (Tables 2 and 3, Figs. 2 and 3). Leaf discs treated with a mixture comprising 33\%-67\% Spinosad resulted in a reduction of leaf consumption and also increased larval mortality 
Table 2 Percent of leaf damage ${ }^{1}$ by the diamondback moth larva on collard greens leaf discs ${ }^{2}$ treated with different insecticide mixtures at the ratios 2:1, 1:1 and 1:2 in laboratory bioassays.

\begin{tabular}{|c|c|c|c|c|c|c|}
\hline \multirow{3}{*}{ Insecticide mixture } & \multicolumn{6}{|c|}{ Percent of leaf damage (\%) after different exposure time at different ratios } \\
\hline & \multicolumn{2}{|c|}{$1: 1$} & \multicolumn{2}{|c|}{$2: 1$} & \multicolumn{2}{|c|}{$1: 2$} \\
\hline & $24 \mathrm{~h}$ & $72 \mathrm{~h}$ & $24 \mathrm{~h}$ & $72 \mathrm{~h}$ & $24 \mathrm{~h}$ & $72 \mathrm{~h}$ \\
\hline Agroneem Plus ${ }^{3}$ & $11.7^{\mathrm{bc}}$ & $23.3^{\text {bcd }}$ & $11.7^{\mathrm{b}}$ & $23.3^{\mathrm{bc}}$ & $11.7^{\mathrm{b}}$ & $23.3^{\mathrm{bc}}$ \\
\hline Pepper extract ${ }^{3}$ & $20.0^{\mathrm{c}}$ & $76.7^{\mathrm{d}}$ & $20.0^{\mathrm{b}}$ & $76.7^{\mathrm{de}}$ & $20.0^{\mathrm{bc}}$ & $76.7^{\mathrm{c}}$ \\
\hline Spinosad $^{3}$ & $0.0^{\mathrm{a}}$ & $0.0^{\mathrm{a}}$ & $0.0^{\mathrm{a}}$ & $0.0^{\mathrm{a}}$ & $0.0^{\mathrm{a}}$ & $0.0^{\mathrm{a}}$ \\
\hline Thiamethoxam $^{3}$ & $0.0^{\mathrm{a}}$ & $0.0^{\mathrm{a}}$ & $0.0^{\mathrm{a}}$ & $0.0^{\mathrm{a}}$ & $0.0^{\mathrm{a}}$ & $0.0^{\mathrm{a}}$ \\
\hline AP & $25.0^{\mathrm{c}}$ & $31.7^{\mathrm{cd}}$ & $21.7^{\mathrm{b}}$ & $28.3^{\mathrm{cd}}$ & $50.0^{\mathrm{c}}$ & $63.3^{\mathrm{c}}$ \\
\hline AS & $0.0^{\mathrm{a}}$ & $0.0^{\mathrm{a}}$ & $0.0^{\mathrm{a}}$ & $0.0^{\mathrm{a}}$ & $0.0^{\mathrm{a}}$ & $0.0^{\mathrm{a}}$ \\
\hline AT & $1.7^{\mathrm{ab}}$ & $1.7^{\mathrm{ab}}$ & $8.3^{\mathrm{b}}$ & $10.0^{\mathrm{b}}$ & $0.0^{\mathrm{a}}$ & $1.7^{\mathrm{ab}}$ \\
\hline PS & $1.7^{\mathrm{ab}}$ & $1.7^{\mathrm{ab}}$ & $0.0^{\mathrm{a}}$ & $0.0^{\mathrm{a}}$ & $1.7^{\mathrm{a}}$ & $1.7^{\mathrm{ab}}$ \\
\hline PT & $1.7^{\mathrm{ab}}$ & $8.3^{\mathrm{abc}}$ & $8.3^{\mathrm{b}}$ & $15.0^{\mathrm{bc}}$ & $0.0^{\mathrm{a}}$ & $1.7^{\mathrm{ab}}$ \\
\hline ST & $1.7^{\mathrm{ab}}$ & $1.7^{\mathrm{ab}}$ & $0.0^{\mathrm{a}}$ & $0.0^{\mathrm{a}}$ & $0.0^{\mathrm{a}}$ & $0.0^{\mathrm{a}}$ \\
\hline Control & $28.3^{\mathrm{c}}$ & $80.0^{\mathrm{d}}$ & $28.3^{\mathrm{b}}$ & $80.0^{\mathrm{e}}$ & $28.3^{\mathrm{bc}}$ & $80.0^{\mathrm{c}}$ \\
\hline
\end{tabular}

${ }^{1}$ Leaf area damage was estimated visually and recorded in $5 \%$ increments; ${ }^{2}$ the leaf discs were divided into four quadrants and each was assessed per $25 \%{ }^{3}$ these were straight insecticides at the label rates.

${ }^{\mathrm{a}-\mathrm{e}}$ Means in a column with the same superscript are not significantly different at $P \leq 0.05$.

AP: Agroneem ${ }^{\circledR}$ Plus and pepper extract; AS: Agroneem ${ }^{\mathbb{B}}$ Plus and Spinosad; AT: Agroneem ${ }^{\mathbb{B}}$ Plus and thiamethoxam; PS: pepper extract and Spinosad; PT: pepper extract and thiamethoxam; ST: Spinosad and thiamethoxam.

(Table 2 and Fig. 2). When thiamethoxam was combined with either Spinosad or Agroneem at the 1:2 ratio, larval mortality was comparable to similar combinations of Spinosad (Fig. 2). A 33\%-50\% inclusion rate of thiamethoxam in a mixture with any of the other insecticides improved the protection of collard leaf discs from consumption by larvae. However, the PT mixture resulted in $60 \%$ leaf consumption and that of PS resulted in greater than $85 \%$ consumption. In other combinations where thiamethoxam was mixed with the other product at 1:1 or $1: 2$, there was significantly $(P<0.05)$ lower mortality than that when Spinosad was used in place of thiamethoxam.

Combinations of Agroneem at $33 \%$ or $50 \%$ in a mixture with thiamethoxam resulted in comparable amounts of leaf consumption (1.7\%) (Table 2). Larval mortality was however $86 \%$ and $94 \%$ with respect to the mixture rates. These mortalities observed for Agroneem in combination with other insecticides are similar to those obtained for Spinosad (Fig. 2). AP combinations were not different from the control. In the 1:2 combinations of AP, leaf damage was higher $(50 \%)$ than that in the control $(21 \%)$ after $24 \mathrm{~h}$ (Table 2).

Treatment mixtures between $12.5 \%$ and $25 \%$, and vice versa, inclusion rates which were effective, resulted in a cumulative increase in leaf damage and adult mortality over time (Table 3 and Fig. 3). With 25\%-75\% inclusion rates of Spinosad combinations resulted in the highest mortalities with concomitant reduction in leaf damage. However, AT combinations caused significantly lower mortalities than the Spinosad treatments. AP in various ratios was the least toxic to larvae and produced very low leaf consumption that was not different from the control (Figs. 3a and 3c). The combinations AP (4:1) and AT (4:1) resulted in similar mortalities, which were not significantly different from the control. AP mixture resulted in mortality similar to that recorded in the control treatment, even though the consumption of leaves treated with AP (38\%-60\%) was lower than the control $(95 \%)$. When the test insecticides were combined at $12 \%-88 \%$ ratios, significant interactions $(P<0.05)$ were found for leaf damage, but not for mortality (Table 3, Figs. 3b and 3d). 


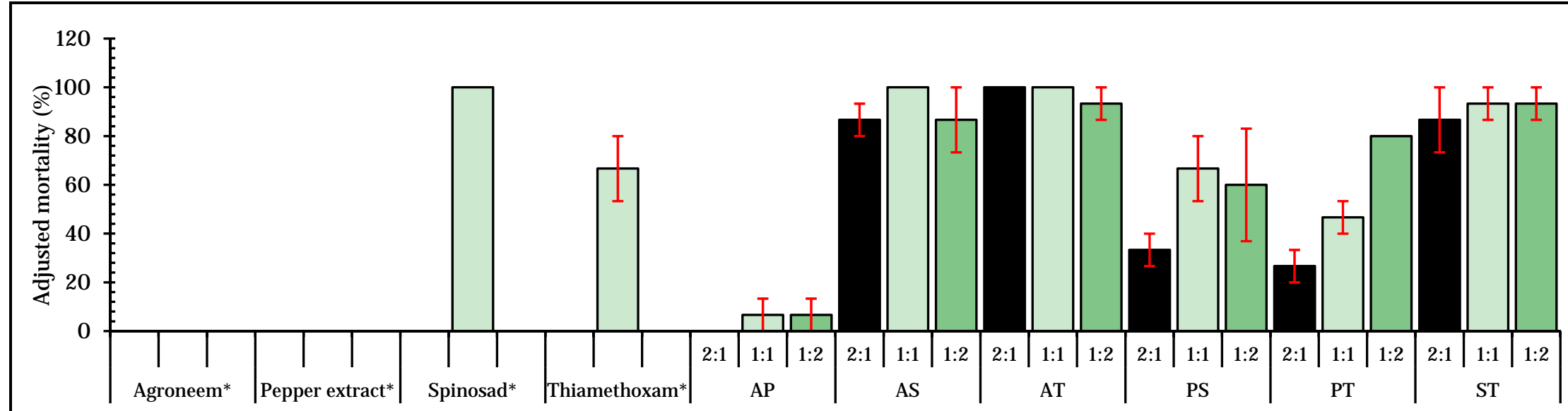

(a) $24 \mathrm{~h}$

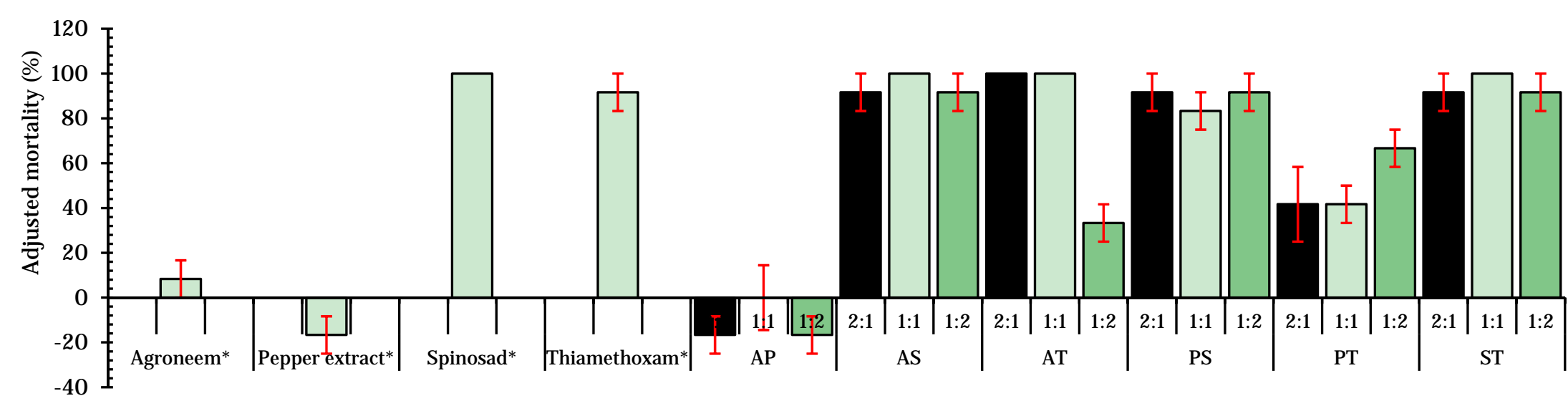

(b) $72 \mathrm{~h}$

Fig. 2 Effect of insecticide mixtures at the ratios: 2:1, 1:1 and 1:2 on mortality of diamondback moth larvae at $24 \mathrm{~h}$ and $72 \mathrm{~h}$ in laboratory bioassays.

AP: Agroneem ${ }^{\circledR}$ Plus and pepper extract; AS: Agroneem ${ }^{\mathbb{P}}$ Plus and Spinosad; AT: Agroneem ${ }^{\circledR}$ Plus and thiamethoxam; PS: pepper extract and Spinosad; PT: pepper extract and thiamethoxam; ST: Spinosad and thiamethoxam.

* These were straight insecticides at the label rates. 
Leaf damage differed between insecticide ratios when reversed in combinations with thiamethoxam (AP and AT), but not for those with Spinosad (PS and ST) ratios (Table 3) where the inclusion of Spinosad appeared to be dominant in the outcome. Relative to the control, all treatment combinations led to a reduction in leaf damage except AP (8:1). The most effective treatments were AT at 1:8, PS and ST at both the $8: 1$ and 1:8 ratios. Mortality trends were somewhat similar to those obtained for the percent of leaf damage. Treatments with PS at the 1:8 ratio and ST at both the 8:1 and 1:8 ratios had significantly $(P<0.01)$ higher mortalities than from the control. Based on leaf damage and mortality figures, these three treatment combinations resulted in excellent protection against larval damage (Table 3). The percent larval mortality from the PS combination was significantly lower than that of Spinosad and thiamethoxam (ST) at the 8:1 ratio, presumably due to higher Spinosad content. AT and $\mathrm{AP}$ at 8:1 ratios demonstrated a similar mortality pattern (Fig. 3) as in the 4:1 ratio, where the reverse ratios had a similar effect (Fig. 2).

\section{Discussion}

The results from this study demonstrate that separate and combined insecticides can have varying effects on the survival and damage potential of diamondback moth larvae. Based on the individual insecticide effects, the mixture effects on the diamondback moth larvae were somewhat predictable. For example, Spinosad was effective as a sole insecticide as well as in mixtures even at low rates. One concern

Table 3 Percent of leaf damage ${ }^{1}$ by the diamondback moth larva on collard greens leaf discs $^{2}$ treated with insecticide mixtures at the ratios $4: 1,1: 4,8: 1$ and $1: 8$ in laboratory bioassays.

\begin{tabular}{|c|c|c|c|c|c|c|c|c|c|c|}
\hline \multirow{3}{*}{ Insecticide mixture } & \multicolumn{10}{|c|}{ Percent of leaf damage (\%) after different exposure time at different ratios } \\
\hline & \multicolumn{2}{|c|}{$1: 1$} & \multicolumn{2}{|c|}{$4: 1$} & \multicolumn{2}{|c|}{$1: 4$} & \multicolumn{2}{|c|}{$8: 1$} & \multicolumn{2}{|c|}{$1: 8$} \\
\hline & $24 \mathrm{~h}$ & $72 \mathrm{~h}$ & $24 \mathrm{~h}$ & $72 \mathrm{~h}$ & $24 \mathrm{~h}$ & $72 \mathrm{~h}$ & $24 \mathrm{~h}$ & $72 \mathrm{~h}$ & $24 \mathrm{~h}$ & $72 \mathrm{~h}$ \\
\hline Agroneem Plus ${ }^{3}$ & $11.7^{\mathrm{bc}}$ & $23.3^{\mathrm{bcd}}$ & - & - & - & - & - & - & - & - \\
\hline Pepper extract ${ }^{3}$ & $20.0^{\mathrm{c}}$ & $76.7^{\mathrm{d}}$ & - & - & - & - & - & - & - & - \\
\hline Spinosad $^{3}$ & $0.0^{\mathrm{a}}$ & $0.0^{\mathrm{a}}$ & - & - & - & - & - & - & - & - \\
\hline Thiamethoxam ${ }^{3}$ & $0.0^{\mathrm{a}}$ & $0.0^{\mathrm{a}}$ & - & - & - & - & - & - & - & - \\
\hline AP & $25.0^{\mathrm{c}}$ & $31.7^{\mathrm{cd}}$ & $33.3^{\mathrm{bc}}$ & $38.3^{\mathrm{c}}$ & $46.7^{b}$ & $60.0^{\mathrm{b}}$ & $68.3^{\mathrm{cd}}$ & $76.7^{\mathrm{bc}}$ & $43.3^{\mathrm{b}}$ & $83.3^{\mathrm{b}}$ \\
\hline AT & $1.7^{\mathrm{ab}}$ & $1.7^{\mathrm{ab}}$ & $5.0^{\mathrm{ab}}$ & $6.7^{\mathrm{b}}$ & $0.0^{\mathrm{a}}$ & $0.0^{\mathrm{a}}$ & $40.0^{\mathrm{bc}}$ & $43.3^{\mathrm{b}}$ & $1.7^{\mathrm{a}}$ & $1.7^{\mathrm{a}}$ \\
\hline PS & $1.7^{\mathrm{ab}}$ & $1.7^{\mathrm{ab}}$ & $0.0^{\mathrm{a}}$ & $0.0^{\mathrm{a}}$ & $0.0^{\mathrm{a}}$ & $0.0^{\mathrm{a}}$ & $1.7^{\mathrm{ab}}$ & $1.7^{\mathrm{a}}$ & $1.7^{\mathrm{a}}$ & $3.3^{\mathrm{a}}$ \\
\hline ST & $1.7^{\mathrm{ab}}$ & $1.7^{\mathrm{ab}}$ & $0.0^{\mathrm{a}}$ & $0.0^{\mathrm{a}}$ & $0.0^{\mathrm{a}}$ & $0.0^{\mathrm{a}}$ & $0.0^{\mathrm{a}}$ & $0.0^{\mathrm{a}}$ & $0.0^{\mathrm{a}}$ & $0.0^{\mathrm{a}}$ \\
\hline Control & $28.3^{\mathrm{c}}$ & $80.0^{\mathrm{d}}$ & $43.3^{c}$ & $95.0^{\mathrm{d}}$ & $43.3^{\mathrm{b}}$ & $95.0^{\mathrm{c}}$ & $75.0^{\mathrm{d}}$ & $96.7^{\mathrm{c}}$ & $75.0^{\mathrm{b}}$ & $96.7^{\mathrm{b}}$ \\
\hline
\end{tabular}

${ }^{\mathrm{T}}$ Leaf area damage was estimated visually and recorded in $5 \%$ increments; ${ }^{2}$ the leaf discs were divided into four quadrants and each was assessed per $25 \%{ }^{3}$ these were straight insecticides at the label rates.

${ }^{\mathrm{a}-\mathrm{d}}$ Means having the same superscript in a column are not significantly different at $P \leq 0.05$.

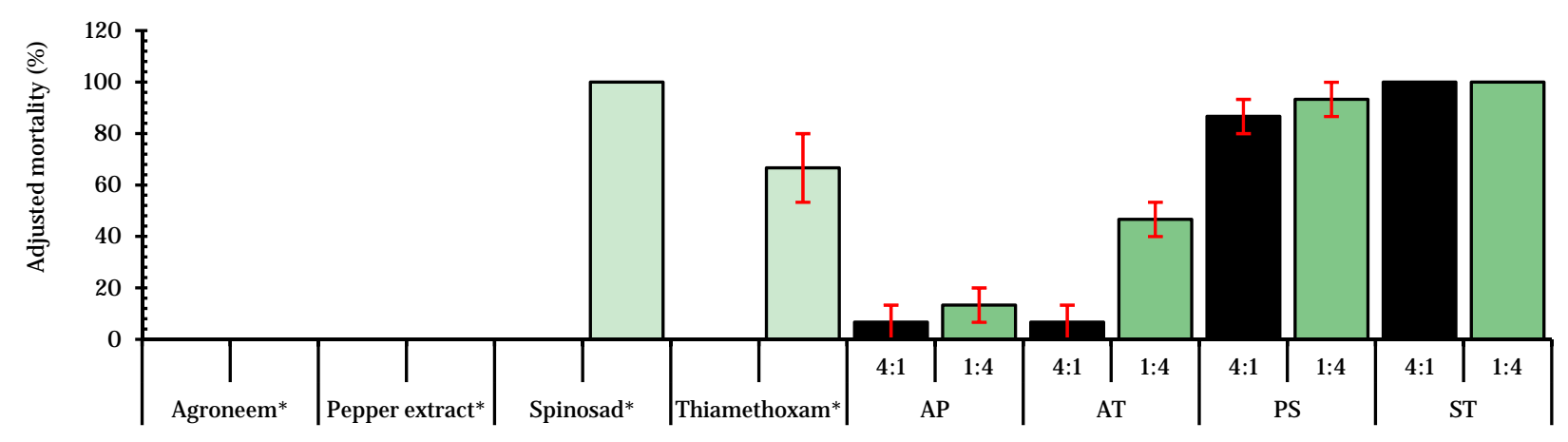

(a) $24 \mathrm{~h}$ 


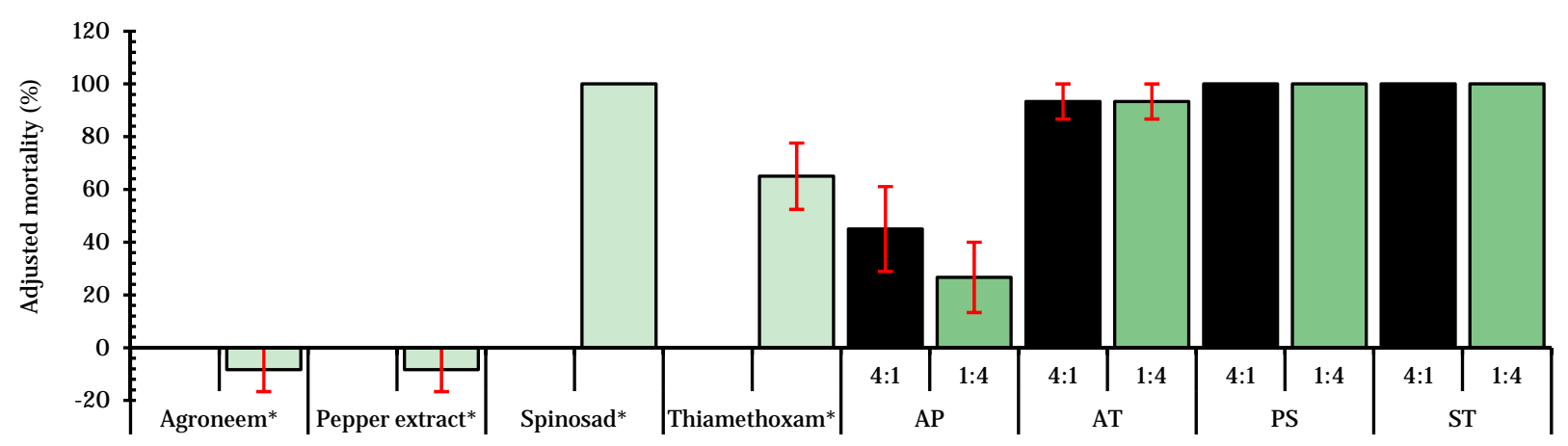

(b) $72 \mathrm{~h}$

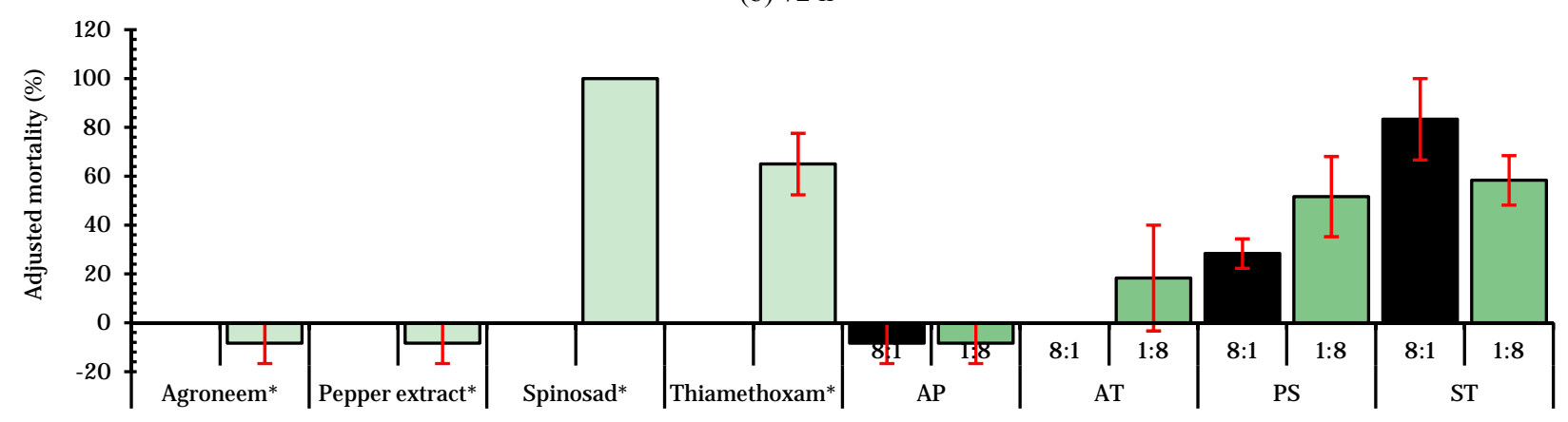

(c) $24 \mathrm{~h}$

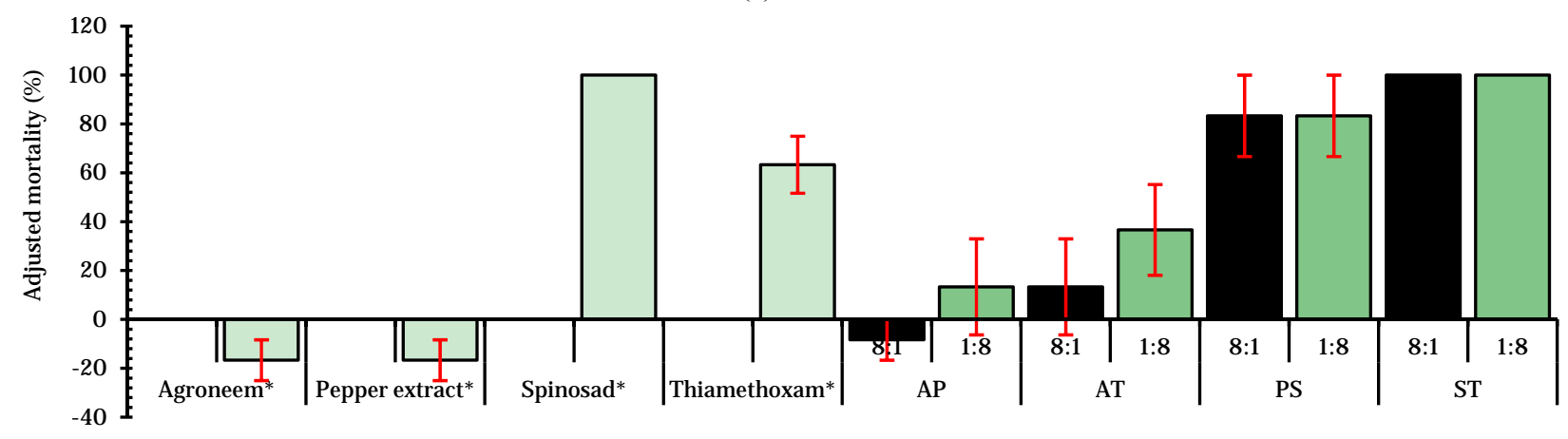

(d) $72 \mathrm{~h}$

Fig. 3 Effect of insecticide mixtures at the ratios of 4:1 and 1:4 or 8:1 and 1:8 on mortality of diamondback moth larvae at $24 \mathrm{~h}$ and $72 \mathrm{~h}$ in laboratory bioassays.

* These were straight insecticides used at the label rates.

was that low rates of Spinosad may lead to resistance build-up over time, especially given the rather short generation time of this insect. Furthermore, the laboratory population used may not be field-hardy. The pepper extract was clearly not effective and needed to be in very high concentrations to show any form of efficacy. The AT combination (4:1) showed possible synergy, as it was more effective than either thiamethoxam at the quarter rate or Agroneem at the double rate. Thiamethoxam in a mixture is recommended as a prophylactic seedling drench treatment in parts of Asia-Pacific region [26] and it is thought to be more persistent than in a foliar application.

Convenience is one reason for mixing pesticides, because it is less time consuming, maybe less costly depending on the ratios, generally less labor intensive to mix and spray at fewer times [27]. Another reason is the potential for improved pest control, such as in increased toxicity or delay in resistance development largely by avoiding frequent use of single classes of 
insecticides [28, 29]. Insecticide usage for the control of P. xylostella is almost similar worldwide, with conventional organophosphates, organochlorines, pyrethroids and carbamates being replaced by novel insecticides, such as cartap, B. thuringiensis, flufenoxuron, fipronil and indoxacarb [30-32] and Spinosad [33-35]. Extensive indiscriminate use of organophosphates, pyrethroids and even novel insecticide chemistries has led to development of resistance in P. xylostella to all of them [31, 32].

The adoption of new pest management strategies has become more complicated and occurs more rapidly [25], but insects have also found ways to rapidly evolve and nullify the gains made. While laboratory studies only provide an indication of likely insecticide activity, it is recognized that this may not necessarily reflect field efficacy. However, direct observations from laboratory experiments with pesticide mixtures under controlled conditions are necessary to completely understand the potential combined action and interactions for specific mixtures that have not been previously studied. When examining the effects of pesticide mixtures, a time-saving approach is for researchers to test each pesticide separately as done in this experiment and then select a few broad combinations to determine if any of the combinations cause important effects. If such effects are detected, one can subsequently partition those combinations into smaller subsets to identify the key chemicals $[22,36]$. In this experiment after the $1: 2$ or $2: 1$ combination, the mixtures in subsequent bioassays were scaled down from six to four combinations when reduced concentrations of $4: 1$ and 8:1 were tested. The AS combination was dropped, since it was the worst of any Spinosad combination, and the PT mixture was also the worst for any thiamethoxam treatment and thus was also dropped.

It has been demonstrated that mixing Spinosad with other insecticides and miticides (imidacloprid, abamectin and bifenazate) in 2-4 way combinations did not negatively affect the ability to control western flower thrips, Frankiniella occidentalis (Pergande) [27]. Results from this study, however, indicated that there is a limit to the effectiveness or the sub-lethal concentration of Spinosad; when PS combination was $1: 8$, there was a decrease in larval mortality. Given the cost of Spinosad, it would probably be better to alternate it (mixture in time rather than in space) with other insecticides, since that would effectively reduce the amount applied over time and therefore the cost of application. Other chemistries could be used to fill the gap [33]. The manufacturer (Dow Agro-Science) recommends only two applications of Spinosad in a season as a resistance management strategy [33], except where there are no alternatives and evidence exists to show that increased and continuous use is profitable and sustainable.

The pepper extract was only relatively effective at its double recommended rate, which was still not comparable to the commercial insecticides. The amounts of pepper needed to achieve such high concentrations are not economically feasible for a pesticide product source that will compete as a human food source. Synthetic capsaicin will be a cheaper alternative [23], but this was not tested in this study, thus there is need for caution in concluding that isolated compounds from natural sources are better. For example, azadirachtin from neem does not appear to do well as the whole plant part extract. Furthermore, capsaicin and dihydrocapsaicin, the pungent components of the pepper fruit, did not correlate with toxicity or repellency to spider mite [24]. This indicates that these compounds are not likely to be related to the toxicity or repellency of the pepper fruit extracts.

In other experiments [37, 38] using three commercial neem products, diamondback moth larvae died by the 7th day and also the products exhibited antifeedant and growth reduction attributes. The low mortality reported here for the Agroneem treatments is more of an indirect effect from a lower leaf intake due to antifeedant properties in the neem treatment [34, 35]. AT mixtures demonstrated the full spectrum of 
defined interactions: synergistic, additive and antagonistic $[39,40]$. There is no doubt that Spinosad can cause $100 \%$ mortality in unexposed or susceptible populations of diamondback moth. The emergence of resistance is the crucial issue that should be mitigated. The mixtures tested when compared to Spinosad by itself can be forecasted to delay insect resistance [10, $24]$ due to an increased number of potent molecules. Therefore, further evaluations of the Spinosad mixtures would be needed in order to determine their ability to delay resistance in diamondback moth populations, effect on adult moths and also their ovicidal properties. In recommending a control toxicant for the diamondback moth, a crucial metric should be the ability to slow the development of resistance, apart from direct mortality and damage. Research should be directed at finding the mechanisms which contribute to the synergy and antagonism of the various insecticide combinations and ratios for these mixtures. The fate of these mixtures under field conditions and the environmental impact should also be a concern. Other factors that need to be considered in future research are potentiation under field conditions and persistence of residues from mixtures. One of the things not evaluated in this study was topical toxicity to the larvae to better understand full spectrum of contact effects. This will need to be evaluated in future studies. Mixtures of biorational insecticides must have benign impact on natural enemies and be suitable for integration with other tactics used in other crop systems, such as organic culture, so that integrated pest management strategies can become fully operational. Finally, new chemistries of both synthetic and biorational products would always need to be evaluated for their potential use in mixtures.

\section{Conclusions}

Given the increasing trends towards organic culture especially among vegetable growers in the United States of America, it is clear that the demand for biorational pesticides is likely to increase. As shown in this study, there are biorational products such as Spinosad that are effective at different dosages in suppression of diamondback moth larvae. To avoid the likelihood of resistance, mixtures with azadirachtin- (or neem) based products, such Agroneem $^{\circledR}$ Plus in this study, should be alternated with Spinosad to prolong its efficacy. Numerous other biorational products are available on the market that can be similarly evaluated singly or in mixtures in the management of the diamondback moth and other pests of crucifers and how best to postpone or avoid the onset of resistance. For the conventional, non-organic grower, there is a wide range of low risk insecticide options, for example thiamethoxam used in this study, that can be used alone or in mixtures (in space or time) with biorational products to minimize the broader environmental impact. Whatever the agricultural practice, no pesticide regimen is without shortfalls, and the use of mixtures is not exempt. Pesticide use will remain on the radar of public opinion for a long time to come. How the acquired knowledge is used will contribute to the direction of this trajectory.

\section{Acknowledgments}

This work was conducted as part of a Master of Science degree project by the first author and was funded by a USDA-NIFA-Evans Allen Grant \# 2010-41534-21452 award to Louis Jackai. Several colleagues made valuable contributions to the research and earlier versions of the manuscript. Their assistance is gratefully acknowledged as well as that from anonymous reviewers.

\section{References}

[1] Gardner, C., Queeley, G., and Brown, B. G. 2010. "Evaluating Fresh Market Yield of Collard Greens Using Traditional and Non-traditional Cultivation Techniques." In Proceedings of the 74th Annual Meeting of FL Academy of Science, 2.

[2] Toth, S. J., Sanders, D. C., Sorensen, K. A., Walgenbach, J. F., Monks, D. W., and Cubeta, M. A. 2003. "Crop 
Profile for Leafy Greens in North Carolina." North Carolina Cooperative Extension Service, North Carolina State University, Raleigh. Accessed July, 2016. http://citeseerx.ist.psu.edu/viewdoc/download?doi=10.1.1 $.688 .884 \&$ rep $=$ rep $1 \&$ type $=$ pdf.

[3] Talekar, N. T., and Shelton, A. M. 1993. "Biology, Ecology and Management of the Diamondback Moth." Annual Review of Entomology 38: 275-301.

[4] Shelton, A. M., Wyman, J. A., Cushing, N. L., Apfelbeck, K., Dennehy, T. J., Mahr, S. E. R., and Eigenbrode, S. D. 1993. "Insecticide Resistance of Diamondback Moth (Lepidoptera: Plutellidae) in North America." J. Econ. Entomol. 86: 11-9.

[5] Grossrieder, M., Kiefer, B., Kang, S. I., and Kuhlmann, U. 2005. "Case Study: Knowledge Transfers in Cabbage IPM through Farmer Participatory Training in DPR, Korea." In Proceedings of the Second International Symposium on Biological Control of Arthropods, 318-32.

[6] Javier, E. Q. 1992. "Foreword." In Proceedings of the Second International Workshop on the Management of Diamondback Moth and Other Crucifer Pests. Taipei: Asian Vegetable Research Development Center Publication, 11.

[7] Morisak, D. J., Simonet, D. E., and Lindquist, R. K. 1984. "Use of Action Thresholds for Management of Lepidopterous Larval Pests of Fresh-Market Cabbage.” J. Econ. Entomol. 77 (2): 476-82.

[8] Ester, A., De Putter, H., and Van Bilsen, J. G. P. M. 2003. "Filmcoating the Seed of Cabbage (Brassica oleracea L. Convar. Capitata L.) and Cauliflower (Brassica oleracea L. Var. Botrytis L.) with Imidacloprid and Spinosad to Control Insect Pests." Crop Prot. 22 (5): 761-8.

[9] Wright, D. 2004. "Biological Control of Diamondback Moth: A Global Perspective.” In Improving Biocontrol of Plutella xylostella, edited by Bordat, D., and Kirk, A. A. Montpellier, France: CIRAD, 9-14.

[10] Jayadevi, H., and Kumar, A. 2011. "Why Is a Crude Extract of Neem Superior to Commercial Neem Formulations? A Field Test against Plutella xylostella L. (Lepidoptera: Plutellidae) in Cabbage." In Proceedings of the Sixth International Workshop on Management of the Diamondback Moth and Other Crucifer Insect Pests, 172-81.

[11] Willmott, A. L., Cloyd, R. A., and Zhu, K. Y. 2013. "Efficacy of Pesticide Mixtures against the Western Flower Thrips (Thysanoptera: Thripidae) under Laboratory and Greenhouse Conditions." J. Econ. Entomol. 106 (1): 247-56.

[12] Wirth, M. C., Jiannino, J. A., Federici, B. A., and Walton, W. E. 2004. "Synergy between Toxins from Bacillus thuringiensis subsp. israelensis and Bacillus sphaericus." J. Med. Entomol. 41 (5): 935-41.
[13] Gill, H. K., and Garg, H. 2014. "Pesticide: Environmental Impacts and Management Strategies." In PesticidesToxic Effects, edited by Solenski, S., and Larramenday, M. L. Rijeka, Croatia: InTech, 187-230.

[14] Schuster, D. J., and Stansly, P. A. 2005. "Biorational Insecticides for Integrated Pest Management in Tomatoes." Accessed July, 2016. http://edis.ifas.ufl.edu/pdffiles/IN/IN48100.pdf.

[15] Zhao, J. Z., Li, Y. X., Collins, H. L., Gusukuma-Minuto, L., Mau, R. F., Thompson, G. D., and Shelton, A. M. 2002. "Monitoring and Characterization of Diamondback Moth (Lepidoptera: Plutellidae) Resistance to Spinosad." J. Econo. Entomol. 95 (2): 430-6.

[16] Tabashnik, B. E., Cushing, N. L., Finson, N., and Johnson, M. W. 1990. "Field Development of Resistance to Bacillus thuringiensis in Diamondback Moth (Lepidoptera: Plutellidae)." J. Econ. Entomol. 83 (5): 1671-6.

[17] Miles, M., and Dutton, R. 2000. "Spinosad: A Naturally Derived Insect Control Agent with Potential Use in Glasshouse Integrated Pest Management Systems.” In Proceedings of the BCPC Conference on Pest and Diseases, 339-44.

[18] Kowalska, J. 2010. "Spinosad Effectively Controls Colorado Potato Beetle, Leptinotarsa decemlineata (Coleoptera: Chrysomelidae) in Organic Potato." Acta Agri. Scand. B-Soil Plant Sci. 60 (3): 283-6.

[19] Gill, H. K., and Dhawan, A. K. 2006. "Global Status of Insecticide Resistance in Helicoverpa armigera on Cotton.” J. Cotton Res. and Dev. 20 (2): 226-31.

[20] Ester, A., De Vogel, R., and Bouma, E. 1997. "Controlling Thrips tabaci (Lind.) in Leek by Film-Coating Seeds with Insecticides.” Crop Prot. 16 (7): 673-7.

[21] Schmutterer, H. 1992. "Control of Diamondback Moth by Application of Neem Extracts." In Proceedings of the Second International Workshop on Management of Diamondback Moth and Other Crucifer Pests, 325-32.

[22] Relye, R. A. 2004. "Growth and Survival of Five Species of Amphibian Species Exposed to Combinations of Pesticides." Environ. Toxicol. Chem. 23 (7): 1737-42.

[23] Antonious, G. F., Meyer, J. E., Rogers, J. A., and Hu, Y. H. 2007. "Growing Hot Pepper for Cabbage Looper, Trichoplusia ni (Hübner) and Spider Mite, Tetranychus urticae (Koch) Control.” J. Environ. Sci. Health B 42 (5): 559-67.

[24] Antonious, G. F., Meyer, J. E., and Snyder, J. C. 2006. "Toxicity and Repellency of Hot Pepper Extracts to Spider Mite, Tetranychus urticae (Koch).” J. Environ Sci. Health B 41 (8): 1383-91.

[25] Abbott, W. S. 1925. "A Method of Computing the Effectiveness of an Insecticide.” J. Econ. Entomol. 18 (2): 


\section{Laboratory Evaluation of Biorational and Low Risk Insecticides and Their Mixtures for Management of Diamondback Moth Larvae}

265-7.

[26] Ahmad, M. 2004. "Potentiation/Antagonism of Deltamethrin and Cypermethrin with Organophosphate Insecticides in the Cotton Bollworm, Helicoverpa armigera (Lepidoptera: Noctuidae)." Pest. Biochem. Physiol. 80 (1): 31-42.

[27] Cloyd, R. A. 2012. "Pesticide Mixtures." Publication of the Agricultural Experiment Station and the Cooperative Extension Service, Kansas State University.

[28] Bielza, P., Fernández, E., Grávalos, C., and Albellán, J. 2009. "Carbamates Synergize the Toxicity of Acrinathrin in Resistant Western Flower Thrips (Thysanoptera: Thripidae).” J. Econ. Entomol. 102 (1): 393-7.

[29] Liu, T., X., Liang, G. M., Xu, Y. Y., Haseeb, M., and Chen, W. 2008. "Adoption of Integrated Management Strategies for Diamondback Moth and Other Crucifer Pests in Texas." In Proceedings of the Fifth International Workshop on Management of Diamondback Moth and Other Crucifer Pests, 312-21.

[30] Mohan, M., and Gujar, G. T. 2003. "Local Variation in Susceptibility of the Diamondback Moth, Plutella xylostella (Linnaeus) to Insecticides and Role of Detoxification Enzymes.” Crop Prot. 22 (3): 495-504.

[31] Saxena, J. D., Rai, S., Srivastava, K. M., and Sinha, S. R. 1989. "Resistance in the Field Populations of the Diamondback Moth to Some Commonly Used Synthetic Pyrethroids.” Indian J. Entomol. 51: 265-8.

[32] Renuka, S., and Regupathy, A. 1996. "Monitoring of Insecticide Resistance in Diamondback Moth in Tamil Nadu." Pestci. Res. J. 8 (2): 168-71.

[33] Amit, S., Thompson, G., and Downward, P. 2001. "Challenges in Implementing Spinosad Diamondback Moth Resistance Management Strategies in Intensive Vegetable Growing Areas in Asia." In Proceedings of the Fourth International Workshop on the Management of
Diamondback Moth and Other Crucifer Pests, 313-8.

[34] Li, Z. M., Liu, S. S., Liu, Y. Q., and Ye, G. Y. 2007. "Temperature-Related Fitness Costs of Resistance to Spinosad in the Diamondback Moth, Plutella xylostella (Lepidoptera: Plutellidae).” Bull. Entomol. Res. 97 (6): 627-35.

[35] Fauziah, I., Mohd-Norazam, M. T., and Mohd-Rasdi, Z. 2012. "Toxicity of Selected Insecticides (Spinosad, Indoxacarb and Abamectin) against the Diamondback Moth (Plutella xylostella L.) on Cabbage." Asian J. Agri. Rural Dev. 2 (1): 17-26.

[36] Relyea, R. A. 2009. "A Cocktail of Contaminants: How Mixtures of Pesticides at Low Concentrations Affect Aquatic Communities.” Oecologia 159 (2): 363-76.

[37] Murugan, K., Jeyabalan, D., Senthil-Kumar, N., and Babu, R., Sivaramakrishnan, S., and Senthil-Nathan, S. 1998. "Antifeedant and Growth Inhibitory Potency of Neem Limonoid against the Cotton Bollworm Helicoverpa armigera (Hübner)." Insect Sci. Appli. 2: 157-62.

[38] Ishida, M., Serit, M., Nakata, K., Juneja, L. R., and Kim, M., and Takahashi, S. 1992. "Several Antifeedants from Neem Oil, Azadirachta indica A. Juss., against Reticulitermes speratus Kolbe (Isoptera: Rhinotermitidae)." Biosci. Biotechnol. Biochem. 56 (11): 1835-8.

[39] Bailar, J., Harris, C. M., Anderson, P. D., Wartenburg, D., Bailey, J., and Laurenson, J. P. 1986. "Synergy: Positive Interaction among Chemicals in Mixtures." J. Pesticide Reform 6 (2): 1-14.

[40] Baker, G. J. 2011. "Crucifer Vegetable Insecticide Resistance Management Strategies and Issues in Australia." In Proceedings of the Sixth International Workshop on Management of the Diamondback Moth and Other Crucifer Insect Pests, 241-7. 